\title{
保安湖浮游物和颗粒有机碎屑现存量 及季节变动与渔业生产・
}

\author{
王少梅 胡传林
}

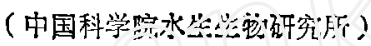

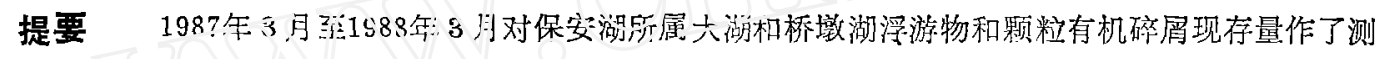

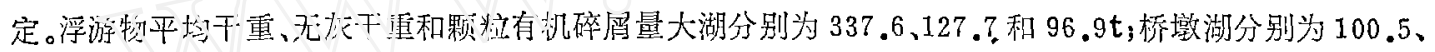
50.3 和 $40,2 \mathrm{t}$ 。浮游物和颗粒有机碎屑现存量具有明显的季节变动。黄丝草、聚草和苦草的碎屑分解对浮 游物的形成起着重要的作用。用浮游物碳量佔算鲢鲜鱼产潜力大湖为 $12.3 \mathrm{~kg} /$ 亩; 桥墩湖为 $11 \mathrm{~kg} /$ 亩。

保安湖位于湖北省东南部大冶县境内 (东径 $114^{\circ} 43^{\prime}$, 北纬 $30^{\circ} 15^{\prime}$ ), 为长江 中下游的 一个中型浅水湖泊, 属梁子湖水系。全湖面积为 61540 亩, 由石栏、土栏、网栏将全湖划分成 五个湖区: 其中大湖 (全湖的主体部分) 为 35000 亩, 桥墩湖为 15000 亩, 肖四海为 2540 亩, 扁担塘为 3000 亩, 保安口为 6000 亩。湖内水草茂密, 主要水草为黄丝草、聚草和苦草。该湖 平均水深 $1.5-2.5 \mathrm{~m}$, 最大水深为 $3.79 \mathrm{~m}$, 水温度变动为 $6.5-31^{\circ} \mathrm{C}$, 全年上下层温度基本相 同, 湖水透明度大, 平均为 $1.57 \mathrm{~m}$ 左右。作者对大湖和桥墩湖的浮游物和颗精有机磁看现存 量及其季节变动作了测定。

\section{方 法}

\section{一、浮游物和颗粒有机碎屏现存量及其碳氮量的测算}

每季度采集水样一次。大湖设两个采样点, 桥墩湖设一个采样点。根据湖水深度, 按 $0.5 \mathrm{~m}$ 的梯度采集混合水样带回实验室, 用经过煆烧处理 $\left(550^{\circ} \mathrm{C}, 2 \mathrm{~h}\right)$ 去掉 滤膜上痕量有机 物 ${ }^{[1,2}$ 的玻璃纤维滤膜 (Whatamat $\mathrm{GF} / \mathrm{C}$ ) 抽滤两个等量水样、烘 烤 $\left(78^{\circ} \mathrm{C}, 24 \mathrm{~h}\right.$ ) 称 重, 其重量减去抽滤前经煆烧处理的滤裳重量即得浮游物干重。然后将此滤膜放入马福炉中

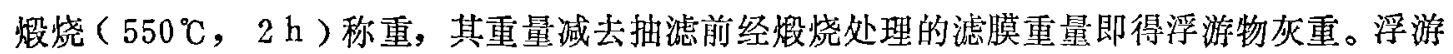
物干重减去浮游物灰重即得浮游物无灰干重 (即有机物重量) [3]。用硝化纤维滤膜 抽 滤水 样, 刮取滤膜上的颗粒物放入称量瓶中烘干, 用元素分析仪 ( CARCO ERBA-1106型) 测得浮游物碳氮量。将浮游物的现存量及碳氮量减去浮游动物和浮游植物的现存量及碳氮量 即得有机碎屑的现存量及碳氮量。浮游植物碳量是根据其叶绿素 $\mathrm{a}$ 量按公式 $\mathrm{C}=74.06+53.21$ ch1 a 计算, 用 $\mathrm{C} / \mathrm{N}=5: 1$ 计算浮游植物氮量 ${ }^{[4]}$ 。

“此题属 “七五”期间国家科研攻关项目的一部分。李纯厚、沈国华和苏泽古等同志为本文提供了有关资料，郑英同志 为插图复墨, 作者一并致㴬。 


\section{二、水草碎屑的分解试验}

保安湖水草生长旺盛期采集黄丝草、聚草和苦草, 风干放进 $8 \times 10 \mathrm{~cm}$ 纱窗 $\left(1 \mathrm{~m} \mathrm{~m}^{2}\right)$ 制成的分解袋中, 分别做室内外分解试验（室内分解试验采用保安湖混合水样）。定期采集 水草和水样测定浮游物干重、无灰干重和碳氮量。

\section{结 果}

\section{一、保安湖浮游物干重、无灰千重、碳期量及.真动态李化}

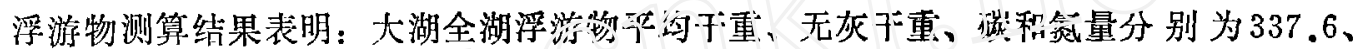

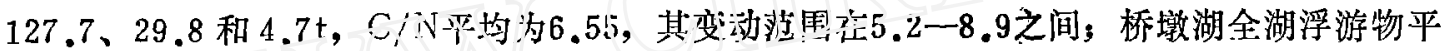

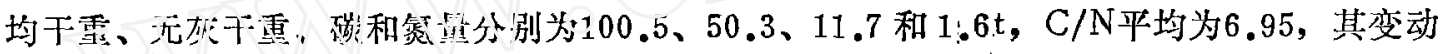
范围在5，5-8.0 方间（目表 1 ）。大湖和桥墩湖浮游物干重、无灰干重和碳氮量的变动具有 明显的攀节变化, 从春季开始, 其量开始上升, 秋季最高, 冬季开始下降。秋季大湖浮游物 干重、无灰干重、碳氮量比其平均量分别高 $38.36 、 35 、 67.4 、 70.56 \%$; 桥墩湖浮游物干 重、无灰干重、碳氮量比其平均量分别高25.68、21.11、38.58、23.15\%（见图 1 ）。

表 1 大湖和桥培湖浮游物千重、无灰千重、碳、氮量

Tab.1 Dry weight, ash-free dry weight and $\mathrm{C}$ and $\mathrm{N}$ content in seston of Dahu and Jiàodunhu Lake

\begin{tabular}{|c|c|c|c|c|c|c|c|c|c|c|}
\hline \multirow{2}{*}{ 季 节 } & \multirow{2}{*}{ 采样点 } & \multicolumn{2}{|c|}{ 浮游物干重 } & \multicolumn{2}{|c|}{ 浮游物无灰于重 } & \multicolumn{2}{|c|}{ 浮游物碳量 } & \multicolumn{2}{|c|}{ 浮游物察量 } & \multirow{2}{*}{$\mathrm{C} / \mathrm{N}$} \\
\hline & & $\operatorname{mg} / \mathrm{L}$ & 总 & $\mathrm{mg} / \mathrm{L}$ & 总 $(\mathrm{kg})$ 量 & $\mathrm{mg} / \mathrm{L}$ & $(\mathrm{kg})$ & $\mathrm{mg} / \mathrm{L}$ & $(\mathrm{kg})$ & \\
\hline \multirow{2}{*}{ 春 } & 大 湖 (I) & 5.878 & 266605 & 1.745 & 79146 & 0.4154 & 18841 & 0.08 & 3630 & 5.2 \\
\hline & 桥墩湖 (I) & 3.455 & 69135 & 1.670 & 33357 & 0.3766 & 7536 & 0.068 & 1361 & 5.5 \\
\hline \multirow{2}{*}{ 夏 } & (I) & 2.999 & 207435 & 2.186 & 151201 & 0.3790 & 26211 & 0.064 & 4435 & 5.9 \\
\hline & (I) & 2.395 & 71885 & 2.104 & 63152 & 0.3860 & 11655 & 0.053 & 1585 & 7.3 \\
\hline \multirow{2}{*}{ 秋 } & (I) & 6.865 & 467055 & 2.535 & 172466 & 0.7323 & 49821 & 0.118 & 8025 & 6.2 \\
\hline & (I) & 4.210 & 126365 & 2.130 & 63932 & 0.5394 & 16150 & 0.067 & 2011 & 8.0 \\
\hline \multirow{2}{*}{ 冬 } & (I) & 9.753 & 409180 & 2.578 & 108160 & 0.5806 & 24361 & 0.065 & 2731 & 8.9 \\
\hline & (I) & 7.485 & 134795 & 2.263 & 40754 & 0.6304 & 11353 & 0.088 & 1576 & 7.0 \\
\hline \multirow{2}{*}{$\begin{array}{l}\text { 平 } \\
\text { 均 }\end{array}$} & (I) & 6.374 & $\sqrt{337569}$ & 2.260 & 127743 & 0.5270 & 29808 & 0.082 & 4705 & 6.55 \\
\hline & (I) & 4.386 & 100545 & 1.990 & 50298 & 0.4840 & 11683 & 0.069 & 1633 & 6.95 \\
\hline
\end{tabular}

\section{二、保安湖颗粒有机碎扂现存量、碳䔬量及其季节变化}

大湖全湖颗粒有机碎屑平均现存量、碳氮量你别为 $96.94 、 13.96 、 2.04 \mathrm{t}, \mathrm{C} / \mathrm{N}$ 平均为 7.296 , 其变动范围在 4.88-10.25之间; 桥墩湖全湖颗粒有机碎屑平均现存量、碳氮量分别 为 $40.3 、 5.51 、 0.119 t, C / N$ 平均为 34.52 , 其变动范围在 $28.13-49.19$ 之间（见表 2 ）。 它们的颗粒有机碎屑现存量及其碳氮量的季节变化与浮游物的季节变化规律是一致的（见图 2 ), 以秋季为最高。秋季大湖颗粒有机碎 屑 现 存量、碳氮量比平均量高 $17.9 、 79.4$ 、 
$19.7 \%$ ，桥墩湖颗粒有机碎首现存量、碳氮量比平均量高 $26.8 、 57.4 、 60.3 \%$ 。

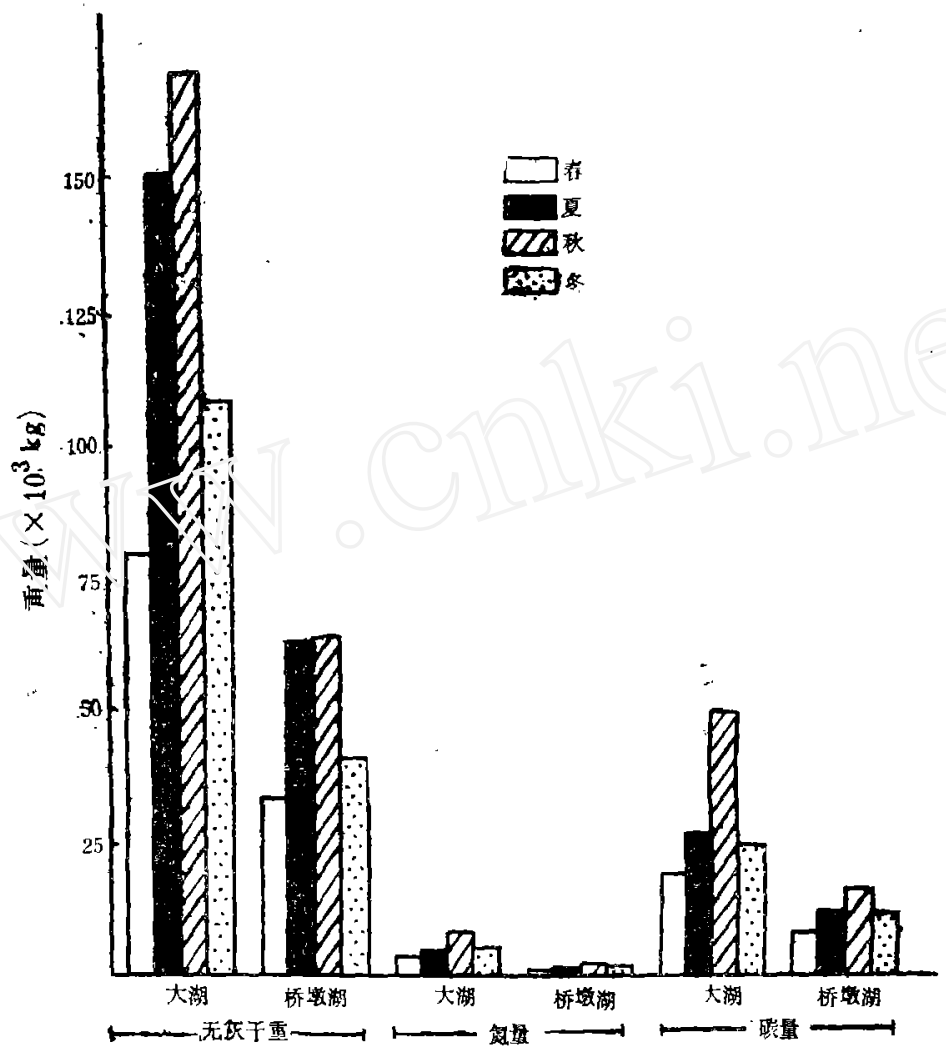

图 1 大湖和桥墩湖浮游物无灰干重、碳氮量的季节变化

Fig.1 Seasonal variations in ash-free dry weight and $\mathrm{C}$ and $\mathrm{N}$ content in seston of Dahu and Jiaodunhu Lake

表 2 大湖和桥墩湖颗粒有机碎屏现有量、碳、氮量

Tab.2 Quantity of particulate organic detritus and $\mathrm{C}$ and $\mathrm{N}$ content in Dahu and Jiaodunhu Lake

\begin{tabular}{|c|c|c|c|c|c|c|c|c|}
\hline 季 & \multirow{2}{*}{ 采样点 } & \multicolumn{2}{|c|}{ 有机碎層现存量（无灰干重） } & \multicolumn{2}{|c|}{ 有机碎首㛶量 } & \multicolumn{2}{|c|}{ 有机碎䏴氦量 } & \multirow{2}{*}{$\mathrm{C} / \mathrm{N}$} \\
\hline 节 & & $\mathrm{mg} / \mathrm{L}$ & 总量 $(\mathrm{kg})$ & $\mathrm{mg} / \mathrm{L}$ & 总量 $(\mathrm{kg})$ & $\mathrm{mg} / \mathrm{L}$ & 总量 $(\mathrm{kg})$ & \\
\hline 春 & 大湖( I & $\begin{array}{l}1.32 \\
1.42\end{array}$ & $\begin{array}{l}59870 \\
28415\end{array}$ & $\begin{array}{l}0.1543 \\
0.1189\end{array}$ & $\begin{array}{l}6998 \\
2879\end{array}$ & $\begin{array}{r}0.03156 \\
0.0026\end{array}$ & $\begin{array}{r}1232 \\
52\end{array}$ & $\begin{array}{r}4.88 \\
46.19\end{array}$ \\
\hline 夏 & (I I ) & $\begin{array}{l}1.55 \\
1.38 \\
\end{array}$ & $\begin{array}{r}107120 \\
41420 \\
\end{array}$ & $\begin{array}{l}0.1244 \\
0.1828\end{array}$ & $\begin{array}{r}8602 \\
5486 \\
\end{array}$ & $0 . \overline{0073}$ & $2 \overline{18}$ & $29 . \overline{25}$ \\
\hline 秋 & $\begin{array}{l}\text { (I) } \\
\text { (I) }\end{array}$ & $\begin{array}{l}1.68 \\
1.70\end{array}$ & $\begin{array}{r}114295 \\
51025\end{array}$ & $\begin{array}{l}0.3682 \\
0.2892\end{array}$ & $\begin{array}{r}25050 \\
8679\end{array}$ & $\begin{array}{r}0.036 \\
0.0103\end{array}$ & $\begin{array}{r}2444 \\
309\end{array}$ & $\begin{array}{l}10.25 \\
28.13\end{array}$ \\
\hline 冬 & $\begin{array}{l}\text { (I) } \\
\text { (I) }\end{array}$ & $\begin{array}{l}2.53 \\
2.23 \\
\end{array}$ & $\begin{array}{r}106480 \\
40160\end{array}$ & $\begin{array}{c}0.3622 \\
-\end{array}$ & $\begin{array}{c}15194 \\
-\end{array}$ & $\begin{array}{c}0.0536 \\
-\end{array}$ & $\begin{array}{c}2248 \\
-\end{array}$ & $\begin{array}{c}6.758 \\
- \\
\end{array}$ \\
\hline $\begin{array}{l}\text { 平 } \\
\text { 均 }\end{array}$ & $\begin{array}{l}\text { (I) } \\
\text { (I) }\end{array}$ & $\begin{array}{l}1.77 \\
1.68\end{array}$ & $\begin{array}{l}96941 \\
40255\end{array}$ & $\begin{array}{l}0.2523 \\
0.1970\end{array}$ & $\begin{array}{r}13961 \\
5515\end{array}$ & $\begin{array}{l}0.040 \\
0.007\end{array}$ & $\begin{array}{r}2041 \\
193\end{array}$ & $\begin{array}{l}7.296 \\
34.52\end{array}$ \\
\hline
\end{tabular}




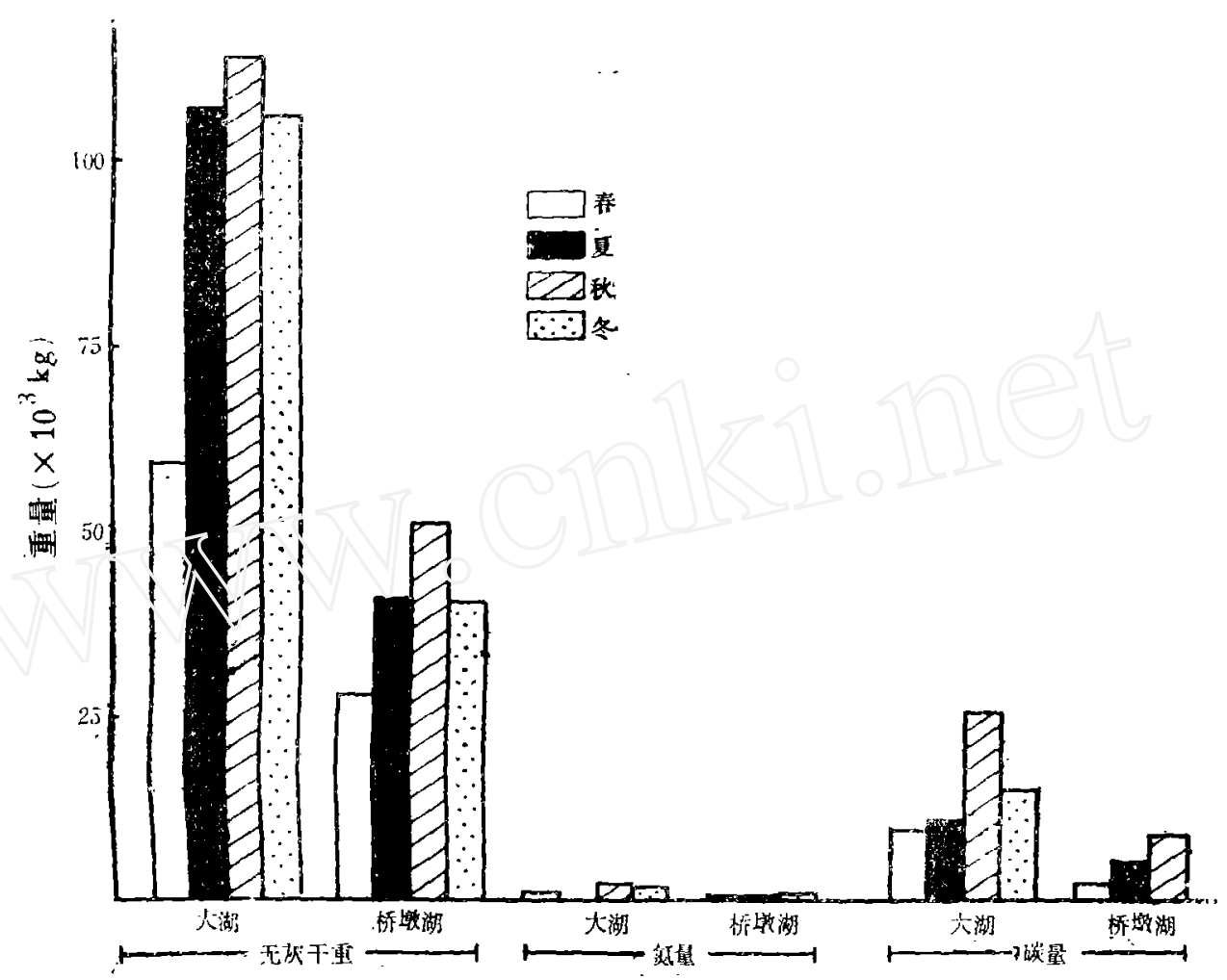

图 2 大湖和桥墩湖颗粒有机碎屑现存量、碳氮量离节变化

Fig.2 Seasonal variations in quantities of particulate organic detritus and $\mathrm{C}$ and $\mathrm{N}$ contents in Dahu and Jiaodunhu Lake

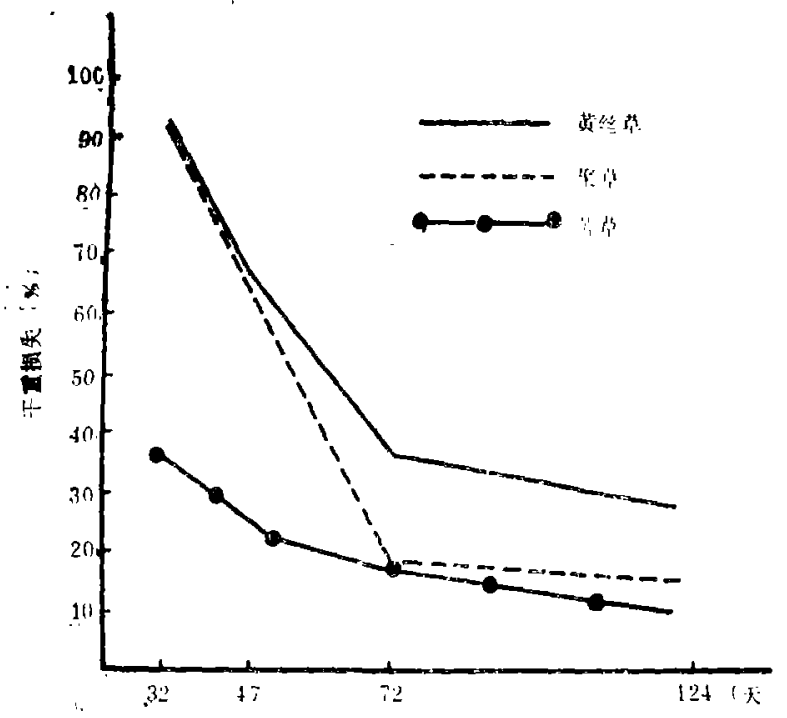

图 3 黄丝草、聚草和苦草分解干重损 失的动态变化

Fig.3 Dynamics of the loss in dry weight during decomposition of Potamog1ton maackianus, $\mathrm{My}$ riophllum spicatum and Vallisneria spiralis

\section{三、水草分解及水草碎屑分解期间浮游物形成动态}

1987年室内水草分解试验表明：苦草、黄丝莌和聚草分解 32 天. 其干重损失分别为始重 
的 $63.3 \% 、 8.0 \%$ 和 $8.4 \%$, 而黄丝草和聚草分解 72 天, 其干重损失才为始重的 $50 \%$ 以上 (见 图 3 ), 这说明苦草的分解速度要比黄丝草、聚草快得多。根据 $W_{t}=W_{o} e^{-k t}$ (式中 $W_{t}$ 是 碎首在 $\mathrm{t}$ 时间的重量, $\mathrm{W}_{\mathrm{o}}$ 是碎首初始时重量, $\mathrm{t}$ 是分解天数, $\mathrm{k}$ 是透度常数 ) 来计算 1988 年 室外烓袋试验结果, 可得苦草的 $k=0.0115 /$ 天, 黄丝草和聚草的 $k=0.0025 /$ 天。Peterson 认为, $k>0.01 /$ 天为快组, $k<0.005 /$ 天为慢组, 因此保安湖苦草的分解属快组, 䇛丝草和 聚草属慢组, 与室内分解速度试验结果一致。

在图 4 中，苦草分解 32 天，其碳氮量的损失为始重的 $50 \%$ 左右; 聚草分解 72 年，其碳的 损失为始重的 $81.78 \%$ ，其氮的损失为始重的 $67.75 \%$ ，黄丝草分解 72 天，其倓的损失为始重

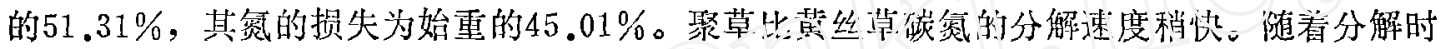

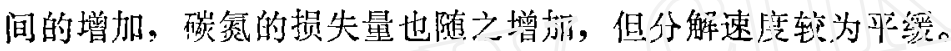

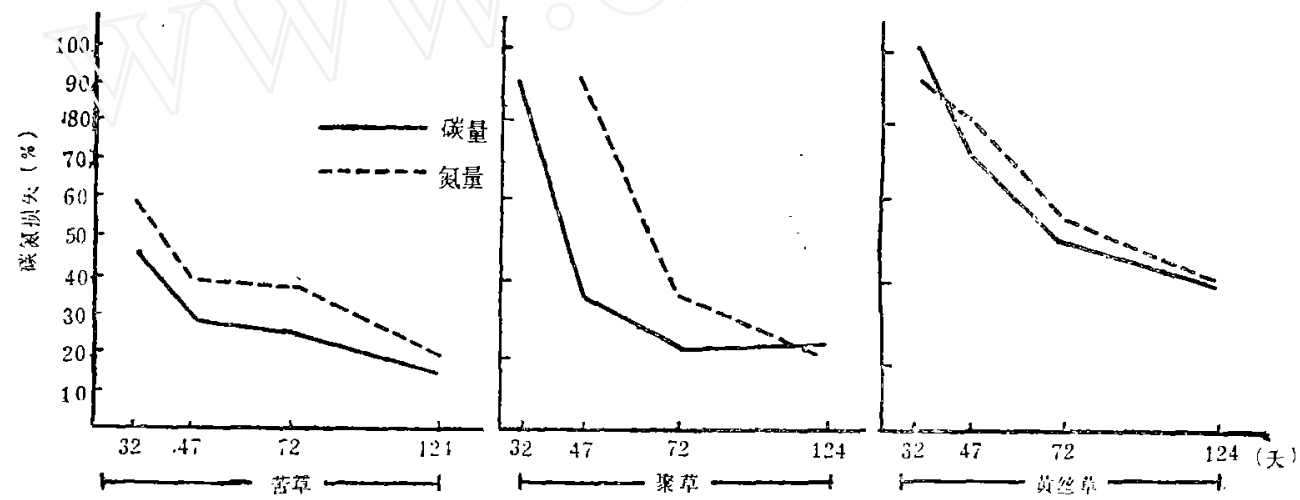

图 4 黄丝草、泉草和苦草分解碳氮损失的动态变化

Fig.4 Dynamics of $\mathrm{C}$ and $\mathrm{N}$ loss during decomposition of Potamoglton maackianus. Myriophllum spicatum and Vallisneria spiralis

三种水草有机物的变化结果表明：苦草分解 32 天，侍机物损失为始重的 $52.2 \%$, 分解 72 天，有机物损失为始重的 $88.8 \%$ 。聚草和黄丝草分解 32 天，其有机物损失分别为始重的 $1.7 \%$

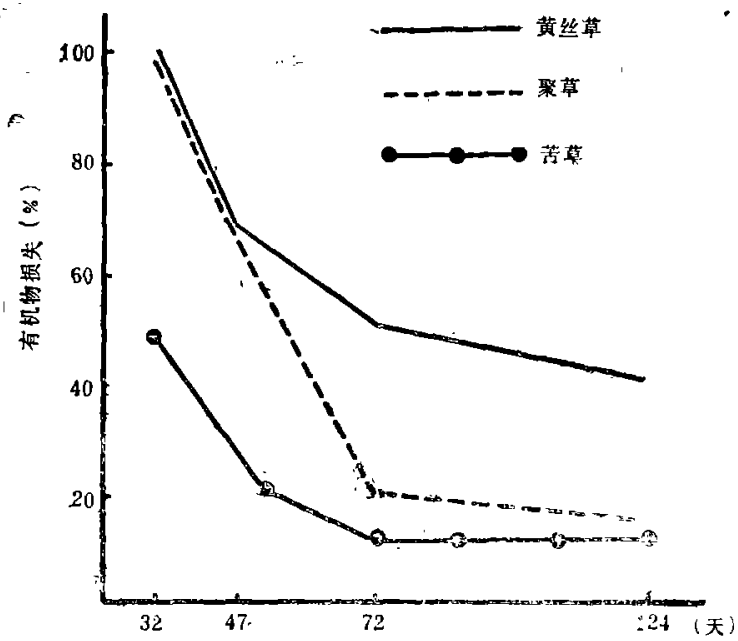

图 5 黄然草、震草和苦草分解有初物损 失动态变化

Fig.5 Dynamics of the loss in the organic matter during decomposition of Potamoglton maackianus, Myriophllum spicatum and Vallisneria spiral is 
和 $0.35 \%$, 分解 72 天，其有机物损失分别为始重的 $80.7 \%$ 和 $50.2 \%$ 。这说明苦草有机物的损 失开始速度很快, 而聚草和黄丝草有机物的损失开始速度很慢（图５）。室内沉淀杯中它们 分解期间水中浮游物形成动态见图 6 。可见, 黄丝草碎屑分解期间水体中浮游物殁成速度平 缓, 聚草碎屏分解期间水体中浮游物碳量形成速度稍快, 三种水草碎屑分解期间水体中浮游 物干重和无灰干重的变化是一致的。
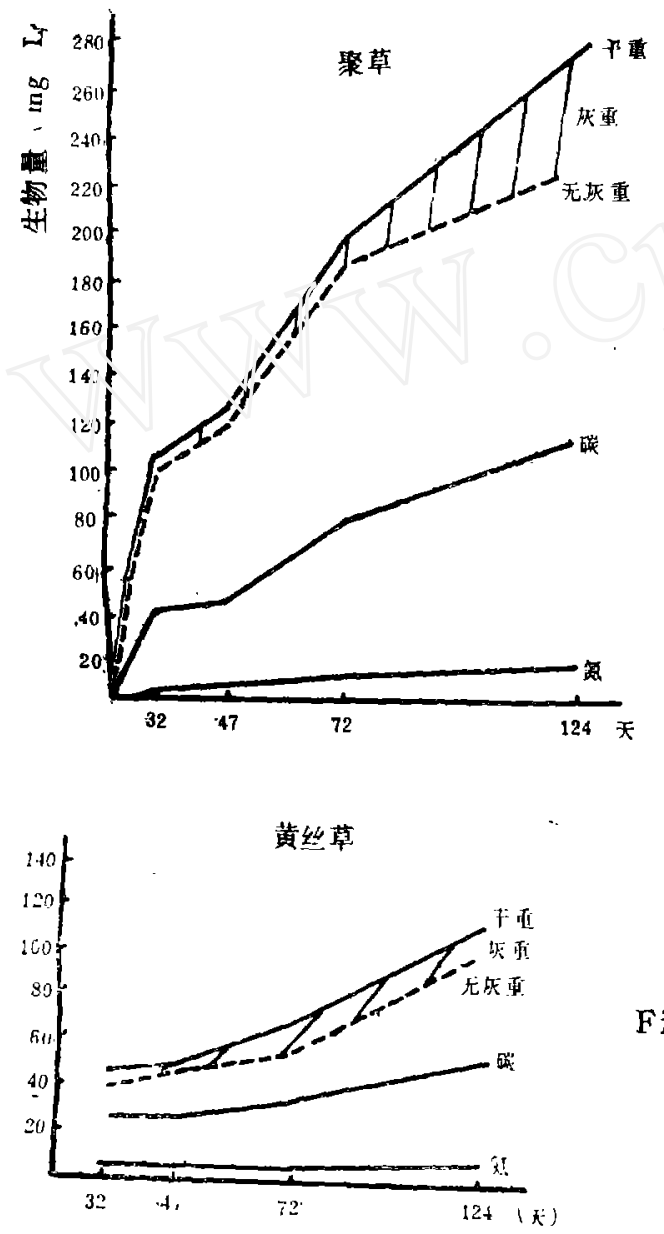

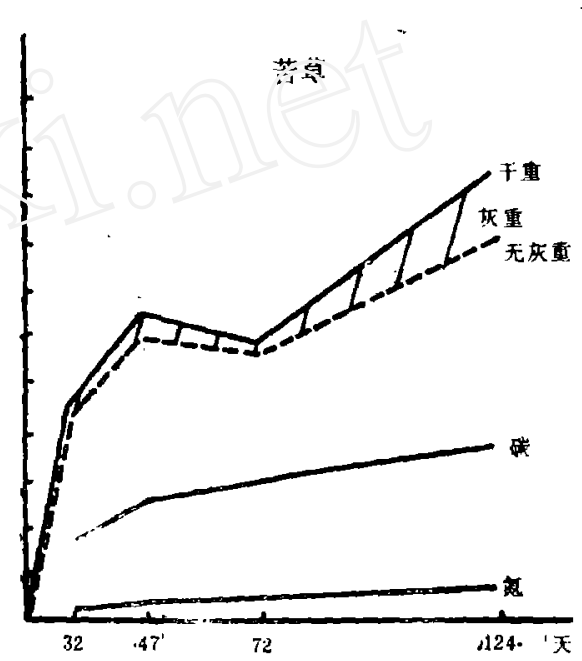

图 6 黄丝草、聚草和苦草碎召分解水体 浮游物 形成动态

Fig.6 Dynamics of the formation of seston during the decomposition of Potamoglton maackianus, Myriophllum spicatum and Vallisneria spiral is

\section{讨 论}

\section{一、水草碎首分解对保安湖浮游物现存量动态的影响}

水生植物在水生生态系统中起着很重要的作用, 它们既能从还原的沉积物中吸收营养形 成生物量，又能通过分泌将这些有机物释放到水中去，也能通过分解使营养物得到重新循环。 因此它们能通过多种途径影响整个湖泊的代谢 $\left.{ }^{5}\right]$ 。黄丝草、聚草和苦草是保安 湖 的优势水 草,生物量最高的是黄丝草（占总生物量的 $66.85 \%$ )，其次是聚草(占总生物量的 $29.43 \%$ )， 其生物量变化以夏季最高、秋季㷅低。根据测算，春季大湖和桥墩湖水草总产媓分别为 $89600 、 31867 \mathrm{t}$; 夏季为 $94955 、 41756 \mathrm{t}$; 秋季为63869、23926t, 具有明显的季节变化。夏 
季水草生长旺盛，除小部分为鱼所食外，其余大部分成为植物碎屑。本试验表明，黄丝草、 聚草和苦草通过碎屑分解，能将自身的养分释放到水体中，因此，它们对保安湖水生态系统 浮游物的形成起着重要作用, 它们的生物量及其变化直接影响水体浮游物现存量及其变化。 水草分解试验表明, 黄丝草和聚草开始分解速度缓慢, 自身养分的损失量和释放到水体中的 养分量是很少的，随着分解时间的延长，分解速度加快，其白身养分的损失量和释放到水体 中的养分量也逐渐增加, 两个月后, 它们的分解速度娍缓, 水体中的养分星继续增加。水草 分解速度变化规律, 也是影响保安湖浮游物现存量季节变化的另一个因䒺。

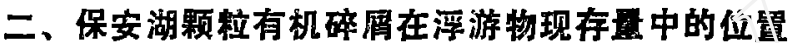

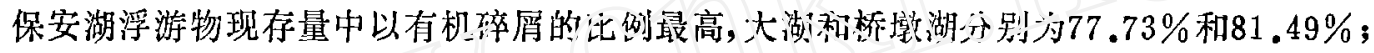

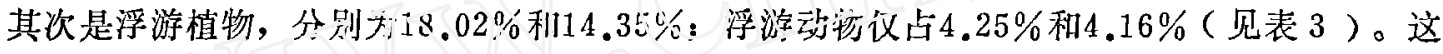

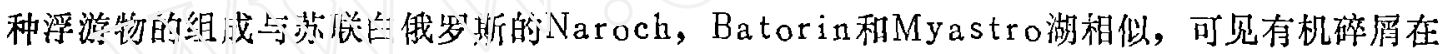
浮游物护占有极重要的位置。

保安湖颗粒有机碎屑 $\mathrm{C} / \mathrm{N}$ 的的波动很大，有机碎屑 $\mathrm{C} / \mathrm{N}$ 值是评价有机碎居营养价值的指 标 ${ }^{[0]}$ 。大湖和桥墩湖颗粒有机碎首的氮量是很低的, 桥墩湖显得更为突出。水体营养价值 不高, 势必影响渔业生产, 因此, 必须合理开发利用。

洨3 各群落占浮游物现存量的比重

Tab.3 Proportions of different types of seston in the total

\begin{tabular}{|c|c|c|c|c|c|}
\hline \multirow{2}{*}{ 㕿 } & \multicolumn{5}{|c|}{ 各群落占浮游物现存量 (\%) } \\
\hline & 采样站 & 浮 游 & 动 物 现 存 量 & 浮游植物现存量 & 有机碎首现存量 \\
\hline \multirow{2}{*}{ 春 } & 大 湖 & & 1.44 & 22.92 & 75.64 \\
\hline & 㭇墩湖 & & 2.54 & 12.43 & 85.03 \\
\hline \multirow{2}{*}{ 夏 } & 大 湖 & & 0.29 & 28.81 & 70.90 \\
\hline & 桥增湖 & & 0.62 & 33.79 & 65.59 \\
\hline \multirow{2}{*}{ 秘 } & 太湖 & & 15.09 & 18.64 & 66.27 \\
\hline & 桥做湖 & & 10.4 & 9.80 & 71.80 \\
\hline \multirow{2}{*}{ 冬 } & 大 湖 & & 0.17 & 1.70 & 98.13 \\
\hline & 杯墽湖 & & 3.09 & 1.37 & 95.54 \\
\hline \multirow{2}{*}{$\begin{array}{l}\text { 平 } \\
\text { 讪 }\end{array}$} & 大 湖 & & 4.25 & 18.02 & 77.73 \\
\hline & 梌墩湖 & & 4.16 & 14.35 & 81.49 \\
\hline
\end{tabular}

\section{三、用浮游物碳量估真鲢鲭鱼产潜力}

保安湖滤食性鱼类主要是指鲢鰙鱼, 其食谱的组成基本上与水体各呴料的组成是一致 的 ${ }^{8]}$ 。保安湖的浮游物是由浮游植物、浮游动物和有机碎屑三部分组成的, 正如表 3 所述, 其中有机碎俤占浮游物的 $80 \%$ 以上。本文采用浮游物估算方法, 只要测定浮游物的碳量, 就 可以通过生物能学的方法计算滤食性血类对饵料碳量的利用率, 进面求出全湖的鱼产潜力。

（1）刘建康等，武昌东湖的水生生物与淊业 (待发表)。 
用浮游物碳量估算滤食性鱼类产量潜力的公式为:

$$
\begin{aligned}
& P_{H y}=\frac{C_{\text {seston }} \cdot \sum P / B n \cdot \sum U_{n} \cdot E \cdot H_{y} \cdot K_{1}\left(H_{y}\right)}{F} \\
& P_{A r}=\frac{C_{s} \underbrace{}_{\text {ton }} \cdot \sum P / B n \cdot \sum U_{a} \cdot E \cdot A_{r} \cdot K_{1}\left(A_{r}\right)}{F}
\end{aligned}
$$

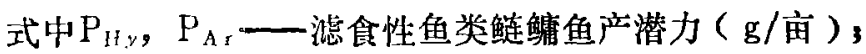

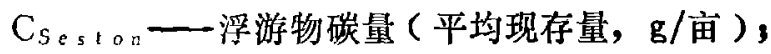

$\Sigma \mathrm{P} / \mathrm{Bn}$ - - 各群落成分的平均 $\mathrm{P} / \mathrm{B}$ 系数;

$\Sigma U_{n}$ 一一鲢鱭鱼对各群落成分的平均利用率;

$\mathrm{F}$ 一一鲢鱝鲜鱼肉的热当量 $\left(5.024 \times 10^{3} \mathrm{~J} / \mathrm{B}\right)$ )

$\mathrm{E}$ 一碳的能星垱量 $\left(1\right.$ 克碳 $=\left(41.868 \times 1 \hat{\mathrm{v}}^{3} \mathrm{~J}_{3}\right)$

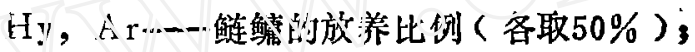

$\mathrm{K}_{1}\left(\mathrm{H}_{\mathrm{y}}\right) ， \mathrm{~K}_{1}(\mathrm{Ar})$ 一鲢鲜的生长效率。

鲢鲕鱼的生长效率 $\left(K_{1}\right)$ 可根据Winberg (1956) 的平衡方程式求出, 其平衡方 程式 为:

$$
\mathrm{C}=\mathrm{P}+\mathrm{R}+\mathrm{F}+\mathrm{U}
$$

式中 $C$ 为摄食能量、 $P$ 为生长能量、 $R$ 为呼吸能量, $F$ 为排粪能量和 $U$ 为排泄能量。已有 研究指出 $(F+U)$ 的能量损失在 $20 \sim 40 \%$ 之间，取高值 $40 \%$ ，则有

$$
\begin{aligned}
& P+R=0.6 C \\
& C=1.67(P+R)
\end{aligned}
$$

根据参考资料 [ ${ }^{[7]}$ 计算 $\mathrm{P} 、 \mathrm{R}$ 和C值。

Iv lew生长效率 $K_{1}$ ( 即第一级生长系数) 为

$$
K_{1} \doteq \frac{P}{C} \text {. }
$$

将鲢鲔的 $\mathrm{P}$ 和 $\mathrm{C}$ 值分别代入上式，得鲢 $\mathrm{K}_{1}(\mathrm{Hy})=6.6 \%$, 鲅 $\mathrm{K}_{1}(\mathrm{Ar})=11.3 \%$ 。 浮游物各群落成分的加权平均 $\mathrm{P} / \mathrm{B}$ 系数 $\Sigma \mathrm{P} / \mathrm{B} n$ 可用下式计算:

$$
\sum \mathrm{P} / \mathrm{Bn}=\mathrm{Pa} / \mathrm{B}_{\mathrm{a}} \mathrm{n}_{1}+\mathrm{P}_{2} / \mathrm{B}_{2} \mathrm{n}_{2}+\mathrm{P}_{\mathrm{d}} / \mathrm{B}_{\mathrm{d}} \mathrm{n}_{\mathrm{d}}
$$

式中 $\mathrm{n}_{1} 、 \mathrm{n}_{2}$ 和 $\mathrm{n}_{\mathrm{d}}$ 分别为浮游藻类、浮游动物和有机碎屑的碳量在浮游物总碳 量中所占 的百分比 $(15 \% 、 5 \% 、 80 \%)$ 。

$\mathrm{P} / \mathrm{B}$ 系数: 浮游植物为 150 , 浮游动物为 50 , 有机碎屑因主要为细菌基质故取 200 。 将这些参数代入得

$\Sigma P / B n=185$ 。

$\sum U_{\mathrm{n}}=\mathrm{U}_{1} \mathrm{n}_{1}+\mathrm{U}_{2} \mathrm{n}_{2}+\mathrm{U}_{\mathrm{d}} \mathrm{n}_{\mathrm{d}}$

式中: $U_{1}$ 是鲢䰹对藻类的利用率，为 $30 \%$ ；

$\mathrm{U}_{2}$ 是鲢鲜对浮游动物的利用率，为 $50 \%$ ，

$\mathrm{U}_{\mathrm{d}}$ 是鲢鳞对有机碎屑的利用率，为 $4 \%$ 。

故 $\Sigma \mathrm{U}_{\mathrm{n}}=10.20 \%$

将上述各参数代入式 ( 1 ) 和式 ( 2 ), 则得

$$
\mathrm{P}_{\mathrm{HY}}=5.189 \mathrm{C}_{\mathrm{seston}}
$$




$$
\mathrm{P}_{\mathrm{Ar}}=8.885 \mathrm{C}_{\mathrm{ses} \text { ston }}
$$

保安湖大湖浮游物碳量平均为 $0.875 \mathrm{~kg}$ /亩, 桥墩湖浮游物碳量平均为 $0.78 \mathrm{~kg} /$ 亩, 代入 以上两式得到大湖鲢鯆鱼产潜力为 $12.3 \mathrm{~kg} /$ 亩, 桥墩湖为 $11 \mathrm{~kg} /$ 亩。

用浮游物碳量来估算滤食性鱼类的鱼产潜力，虽能较全面的反映水体中各种组料的产鱼 能力, 但也存在选用参数时产生的误差, 而且有机碎屑和细菌在鲢鲜营养中的实际价值有待 进一步研究。

\title{
考文嘼
}

[1] Holm-Hansen. The distribution and chemical crmpositio/s of farticulate maierial in marine and fresh waters. Mem.Ist. Lial Id-obiol. 29 (supfl), 37-5!, i972.

[2] Moss B. Seston compcsition in two fresiwaler facis. Limnol.Oceemogr.15, 504-513, 1970.

[3] Sa:aiers. G. W The tras formation of artificial detritus in lake waters. Mem Ital Idrobiol $\therefore S\left(s \alpha_{1} p\right), 26 i-282,1972$

[4] 林施莲等，武汉东湖浮游植物各种成份分析与沉淀物中浮游植物活体碳、氮、磷的测定，水生生物学报，9(4) 359-364, 1985.

[5] Godlewska-Lipowa. W. A. Bacteria as in dication of lakes. Pol. Arch, Hydrobiol. 23, 341-356. 1976.

[6] Taylor. B. R. and J. C. Roff. Use of ATP and Carbon: nitrogen ratio as indicators of food guality of stream detritus Freshwat. Biol. 14, 195-201, 1984

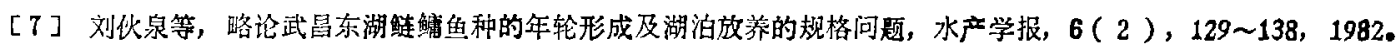

\section{QUANTITIES AND SEASONAL VARIATIONS IN SESTON AND PARTICULATE ORGANIC DETRITUS IN BAOAN LAKE AND THEIR RELATION TO. FISHERIES PRODUCTION}

\author{
Wang Shaomei Hu Chuanlin \\ (Institute of Hydrob:ology, Academia Sinica)
}

\begin{abstract}
From March 1987 to March 1988, measurements were taken on the quantities of seston and particulate organic detritus in two areas of Baoan Lake, Dahu and Jiaodunhu. The average dry weight of seston was 337.6 and 100.5 tons in Dahu and Jiaodunhu respectively. The ash-free dry weight of seston was 127.7 and 50.3 tons in Dahu and Jiaodunhu respectively. The quantity of particulate organic detritus was 96.9 and 40.2 tons in Dahu and Jiaodunhu respectively, Showing apparent seasonal variations in the quantities of seston and particulate organic detritus. The decomposition of Potamoglton maackianus, Myriophllum spicatum and Vallisneria spiralis are important in the formation of seston. Estimated from the amount of carbon in the seston, the potential production of silver carp and bighead carp is 12.3 and $11 \mathrm{~kg} / \mathrm{mu}$ at Dahu and Jiaodunhu respectively.
\end{abstract}

